\title{
FILOSOFIA, LITERATURA E DESCRENÇA NO DIÁLOGO ENTRE UM PADRE E UM MORIBUNDO DO MARQUÊS DE SADE
}

\section{PHILOSOPHY, LITERATURE AND DISCRETION IN THE DIALOGUE BETWEEN A PRIEST AND A MORIBUND OF THE MARQUIS DE SADE}

Marcelo de Sant'Anna Alves Primo

\begin{abstract}
RESUMO: Que Sade foi um filósofo, literato e ateu não se tem a menor dúvida. Nesse sentido, o objetivo do presente artigo é mostrar como se articulam as três facetas supracitadas do marquês na leitura do seu texto inaugural Diálogo entre um padre e um moribundo, de 1782. Através do estilo e estrutura clássicos do diálogo, o escritor desfere contundentes ataques, ambientado em uma alcova, resultando em: 1) a crítica à exploração do medo nos homens pelos cristãos no momento da morte; 2) e, consequentemente, recusa a existência de deus quando opõe a razão e os sentidos às quimeras religiosas. Contudo, Sade vai muito mais além do que usar a arte do diálogo filosófico para encarar tête-à-tête os dogmas da religião: a defesa de uma postura serena diante da morte não significa ficar somente no plano do discurso, já que o subverte introduzindo a ação em vez de explicar através de conceitos o que seria a natureza corrompida do homem. Logo, podemos concluir que o Diálogo passa dos limites de uma simples manifestação literária do materialismo ateu sadeano sendo, na verdade, um autêntico escrito de resistência que, tendo como marco inicial o desamparo do homem, afirma o corpo para superá-lo explorando os prazeres corporais ao extremo.
\end{abstract}

Palavras-chave: Sade. Filosofia. Literatura. Ateísmo.

\begin{abstract}
That Sade was a philosopher, literary and atheist is in no doubt. In this sense, the objective of this article is to show how the three facets of the marquis articulate above in the reading of his inaugural text Dialogue between a priest and a dying man, from 1782. Through the classic style and structure of the dialogue, the writer unlocks blunt attacks, set in an alcove, resulting in: 1) the criticism of the exploitation of fear in men by Christians at the time of death; 2) and, consequently, refuses the existence of god when he opposes reason and the senses to religious chimeras. However, Sade goes much further than using the art of philosophical dialogue to face tête-à-tête the dogmas of
\end{abstract}


religion: the defense of a serene stance in the face of death does not mean staying only on the plane of discourse, since it subverts it by introducing the action instead of explaining through concepts what would be the corrupted nature of man. Therefore, we can conclude that the Dialogue goes beyond the limits of a simple literary manifestation of Sadean atheistic materialism, being, in fact, an authentic writing of resistance that, having as a starting point the helplessness of man, affirms the body to overcome it exploring the pleasures bodily effects to the extreme.

Keywords: Sade. Philosophy. Literature. Atheism.

Filosofia, literatura e descrença no Diálogo entre um Padre e um Moribundo do Marquês de Sade

\begin{abstract}
"A natureza nos ensina: saís deste mundo como nele entrastes. Passastes da morte à vida sem que fosse por efeito de vossa vontade e sem temores; tratai de vos conduzirdes de igual maneira ao passardes da vida à morte; vossa morte entra na própria organização do universo: é um fato que tem seu lugar assinalado no decurso dos séculos".
\end{abstract}

XX.

MONTAIGNE, Ensaios,

"Portanto, bani para sempre de vossos corações uma doutrina que contradiz igualmente vosso deus e vossa razão. Este é provavelmente o dogma que mais produziu ateus na terra, não havendo homem algum que não prefira acreditar em nada a adotar um amontoado de mentiras tão perigoso; eis porque tantas almas honestas e sensíveis acreditam serem obrigadas a buscar na irreligião absoluta consolos e recursos contra os terrores com os quais a infame doutrina cristã tenta subjuga-las. Livremo-nos, portanto desses vãos temores; calquemos para sempre os dogmas, as cerimônias, os mistérios dessa abominável religião. $\mathrm{O}$ ateísmo mais enraizado vale mais do que um culto cujo perigos acabamos de expor."

Sade, Do inferno. 
Para iniciarmos as considerações e reflexões a respeito da tríade filosofialiteratura-descrença que permeia e caracteriza os escritos de Sade, aludo aqui a um artigo de Annie Le Brun, "L'athéisme, littéralement et dans tous les sens" ${ }^{1}$, no qual a autora analisa minuciosamente e faz vir à tona toda a grandeza literária e filosófica do escrito do marquês Os cento e vinte dias de Sodoma. Fazendo uma adição ao título do texto supracitado, e para os propósitos deste texto, penso que o ateísmo de Sade se mostra literalmente e literariamente em seus escritos, através de diversos diálogos filosóficos desenvolvidos por seus personagens. Em sua estreia no métier literário do século XVIII francês com o Diálogo entre um padre e um moribundo, Sade não hesita em momento algum quando entende que quem tiver essa obra em mãos, terá uma bela oportunidade de ver quem realmente é o homem². Segundo Eliane Robert Moraes, nos moldes estruturais clássicos de um diálogo platônico, tal escrito mostra "a audácia de um escritor que, em pleno século XVIII, transtorna a paisagem sensível de sua época [...]" com "uma densa argumentação filosófica fundadas nas teses materialistas que refutam a existência de Deus" (2006, p. 27). Todavia, Sade atribui à arte do diálogo filosófico um propósito específico: enfrentar de frente os dogmas da religião. A defesa de uma postura serena diante da morte significa a subversão discursiva absoluta, dando um papel primordial à ação em vez de se limitar a tentativas de explicações conceituais acerca do significado da natureza corrompida do homem. Assim, lendo acuradamente o Diálogo, é possível perceber que o marquês ultrapassa as fronteiras de seus aspectos estilísticos literários e privilegiando o conteúdo do seu materialismo ateu ${ }^{3}$. Na verdade, o texto é um claro manifesto de

\footnotetext{
${ }^{1}$ Presente na coletânea de artigos Lire Sade, organizada por Norbert Sclippa.

${ }^{2}$ Sendo o que, "por assim dizer, abriu definitivamente as comportas ao manancial furioso da verve sadiana" (BORGES, 2001, p. 13).

${ }^{3}$ Segundo Olivier Bloch, “[...] o materialismo, embora nem sempre seja revolucionário (nos domínios político e social, os materialismos conservadores estão longe de constituir exceções), tem sempre um caráter subversivo e redutor das ideias recebidas. A continuidade crítica inerente à tradição materialista exprimese particularmente no recurso a um arsenal de argumentos opostos às hierarquias idealistas de tipo religioso ou filosóficas" (1987, p. 19). Para Yvon Quiniou, o materialismo ateu, com seu teor anti-religioso por excelência, "implique eu l'on renonce à une certaine représentation de Dieu et de son intervention dans le monde, et donc, si je puis dire, au Dieu de cette représentation" (2004, p. 18, itálicos do autor).
} 
resistência a dogmas que tem como ponto de partida o desamparo ${ }^{4}$ do homem e afirma o corpo para superar a sua própria condição explorando os prazeres corporais ao extremo.

Inaugurando o diálogo, o padre pergunta ao moribundo se não está arrependido de incorrer em todos os erros e vícios advindos das desordens que o levou a uma condição frágil e débil, quando mostrado o tableau de todas as suas ações atrozes. Tendo pouco tempo de vida, ele poderá aproveitar os seus remorsos para obter dos céus a absolvição de suas faltas, sendo isso possível unicamente através do sacramento da penitência. $\mathrm{O}$ moribundo responde que se arrepende, porém - e o que escapa à compreensão do padre - não das consequências morais de seus atos, mas por não ter usufruído mais das suas faculdades naturais:

MORIBUNDO: - Eu disse que me arrependo.

PADRE: - Já o dissestes.

MORIBUNDO: - Mas não compreendeste.

PADRE: - O quê?!

MORIBUNDO: - O seguinte: criado pela natureza, com apetites muito vivos e paixões muito fortes, posto neste mundo unicamente para entregar-me a eles e satisfazê-los, sendo tais efeitos de minha criação apenas necessidades relativas aos primeiros fins da natureza, ou, se preferires, derivações essenciais de seus projetos sobre mim, todos em razão de suas leis, só me arrependo de não ter conhecido o bastante a sua onipotência, e meus únicos remorsos são pelo uso medíocre que fiz das

\footnotetext{
${ }^{4}$ Penso aqui na noção sartreana de desamparo, em $O$ Existencialismo é um humanismo, quando um deus não dá mais conta dos rumos da existência humana, sendo incapaz de traçar a priori um futuro para a mesma: "O existencialista não pensará nunca, também, que o homem pode conseguir o auxílio de um sinal em qualquer que o oriente no mundo, pois considera que é o próprio homem quem decifra o sinal como bem entende. Ponge escreveu num belíssimo artigo: 'O homem é o futuro do homem'. É exatamente isso. Apenas, se por essas palavras se entender que esse futuro está inscrito no céu, que Deus pode vê-lo, então a afirmação está errada, já que, assim, nem sequer seria um futuro. Se se entender que, qualquer coisa que seja o homem que surja no mundo, ele tem um futuro a construir, um futuro virgem que o espera, então a expressão está correta. Porém, nesse caso, estamos desamparados" (1987, p. 9-10). Todavia, segundo Eliane Robert Moraes, "como se antecipasse a fórmula gramsciana - 'pessimismo da razão, otimismo da ação' o libertino procura superar esse desamparo primordial explorando os prazeres do corpo até suas derradeiras potencialidades. A volúpia, ensina o devasso do Diálogo ao padre, [...] apenas ela pode substituir a consolação que a promessa de vida eterna encerra para atenuar o sofrimento humano, assegurando ao ateu uma outra forma de permanência do mundo" (2006, p. 31).
} 
faculdades (criminosas para ti, tão simples para mim) com que me dotou para servi-la. Por vezes the resisti e arrependo-me por isso. Cego pelo absurdo de seus sistemas, combati por eles toda a violência dos desejos recebidos por uma inspiração mais divina. Disso me arrependo. Só colhi flores quando poderia ter feito uma ampla colheita de frutos. Eis os justos motivos de meus arrependimentos; estima-me bastante para eu não procurar outros (SADE, 2001, p. 19-20).

Atônito, o padre exclama que até que ponto os supostos erros e sofismas conduzem a fala do moribundo, tentando convencê-lo que as suas infelizes inclinações de sua natureza corrompida o levaram sucessivamente desvios e infortúnios proporcionados por sua conduta hedonista. O criador seria o senhor de todas as coisas, que fez tudo e conserva o que criou por efeito de sua onipotência. O moribundo aproveita a deixa e fustiga, questionando o seu interlocutor o significado dos termos "criador" e "natureza corrompida", apontando o contrassenso de um grande senhor todopoderoso criar naturezas corrompidas. Se o livre-arbítrio concedido aos homens possibilitasse-lhes fazer sempre o bem e nunca o mal na terra, um deus não precisaria testar ou atentar a sua criação a todo momento, já que conhece perfeitamente as suas criaturas e nunca duvidando do resultado de suas ações livres, de suas escolhas (SADE, 2001). Todavia, se uma divindade tivesse o poder de fazer sempre com que escolhessem o bem, por que se corrompem? O padre tergiversa, dizendo que lhe é ininteligível os desígnios divinos, não sendo possível a ninguém compreendê-los ${ }^{5}$.

O diálogo toma um rumo que ao moribundo fica impossível esconder a sua descrença numa concepção divina da natureza. Esta, bastando a si mesma em tudo

\footnotetext{
${ }^{5}$ Dificuldade levantada pelo moribundo contra o seu opositor bem expressa neste trecho: "PADRE - Quem pode compreender os desígnios imensos e infinitos de Deus sobre o homem e quem pode compreender tudo o que vemos? MORIBUNDO - Quem simplifica as coisas, meu amigo, e, sobretudo não multiplica as causas para melhor confundir os efeitos. Por que colocas outra questão quando não me podes explicar a primeira? Sendo possível que a natureza tenha feito sozinha tudo o que atribuis a teu Deus, por que pretendes arrumar-lhe um senhor? A causa do que não compreendes talvez seja a coisa mais simples do mundo. Aperfeiçoa a tua física e entenderás melhor a natureza; purifica a tua razão, elimina teus preconceitos e não necessitarás mais desse deus" (2001, p. 20-21). Doze anos antes do Diálogo de Sade, Holbach em seu Système de la nature, afirma que um melhor conhecimento de física no que concerne às relações de causa e efeito no curso da natureza requer um melhor estudo que, mesmo em uma época "iluminada" pela razão, ainda é empreendido por poucos: "Peu d'hommes, même de nos jours, ont suffisamment étudié la nature, ou se sont mis au fait des causes diverses \& des effets qu'elles doivent produire" (2011, II, i, p. 6).
} 
que concerne à criação, conservação e transformação em seu sistema, não tem mais sentido em atribuir à mesma uma causa que lhe seja externa. A fala do padre, multiplicando as causas confunde os efeitos, colocando questões sobre questões sem explicar coisa alguma. Eivado de preconceitos, repudia a física e a razão, acusando o moribundo de uma cegueira ateia que o impossibilita de ver e sentir as "provas" da existência de um criador. Em resposta, o moribundo circunscreve o que entende por "crer":

PADRE: - Seu infeliz, pensei que fosse apenas sociniano!...Tinha armas para combater-te, mas vejo bem que és ateu! E já que teu coração se nega à imensidade das provas autênticas que recebemos todos os dias da existência do criador, nada mais tenho a te dizer. Não se devolve a luz a um cego.

MORIBUNDO: - Meu amigo, conforma-te com a evidência de cego é quem se veda com uma fita, não quem a arranca dos olhos. Tu edificas, inventas, multiplicas; eu destruo, simplifico. Tu acumulas erros sobre erros; eu combato todos. Qual de nós é o cego?

PADRE: - Então não crede mesmo em Deus?

MORIBUNDO: - Não, por uma razão bem simples. É perfeitamente impossível crer no que não se compreende. Entre a compreensão e a fé devem existir relações imediatas. A compreensão é o primeiro alimento da fé. Onde a compreensão falha, a fé está morta (SADE, 2001, p. 21).

Mostrando o quão enganoso é crer sem compreender o que seja a natureza, o moribundo aporeticamente desafia o padre a demonstrar o que é esse deus criador. A sua confissão diante da morte agora ganhou contornos de um verdadeiro desafio a provar-lhe com argumentos razoáveis o caráter divino da ordem e da dinâmica das coisas naturais. O moribundo elenca duas "provas" que poderiam jogar a favor do seu interlocutor, que seriam a prova de que a matéria é inerte e que a natureza não basta a si própria. ${ }^{6}$ É possível crer no sol porque ele é visível, concebido como "o centro de reunião de toda a matéria inflamável da natureza, aceito sua marcha periódica sem espantar-me. É uma operação física, talvez não tão simples quanto a

\footnotetext{
6 “Até então não esperes nada de mim. Só me rendo à evidência que recebo dos sentidos; onde eles cessam, minha fé desfalece” (SADE, 2001, p. 21).
} 
da eletricidade, mas que não nos é permitido compreender. Para que ir mais longe?" (Ibid., p. 22).

Lançando a tese que a natureza levou o homem, devido a ser formado por órgãos arranjados em razão de seus objetivos e necessidades, a tender tanto à virtude como ao vício, o moribundo faz com que o padre inicie a sua reflexão sobre a necessidade das coisas no mundo. E se tudo é necessário, tudo é regulado, contudo, quem opera essa regulação? E nela há alguma sabedoria? Ou tudo pode derivar de uma causa primeira sem ter sabedoria alguma regendo por trás?

PADRE: - Sendo assim, tudo é necessário no mundo.

MORIBUNDO: - Seguramente.

PADRE: - Mas se tudo é necessário, não está tudo regulado?

MORIBUNDO: - E quem diz o contrário?

PADRE:- E quem pode regular tudo como está a não ser uma mão onipotente e sábia?

MORIBUNDO: - Não é necessário que a pólvora inflame ao lhe atear fogo?

PADRE: - Sim.

MORIBUNDO: - E que sabedoria vês nisso?

PADRE: - Nenhuma.

MORIBUNDO: - Portanto, é possível ter haver coisas necessárias sem sabedoria, e possível, consequentemente, tudo derivar de uma causa primeira sem haver nessa causa razão ou sabedoria (SADE, 2001, p. 2223).

$\mathrm{O}$ argumento do moribundo consiste em tentar mostrar que as coisas podem ser $\mathrm{o}$ que são e serem vistas sem que sabedoria ou razão alguma as conduzam, e aos efeitos naturais é forçoso terem causas naturais sendo desnecessário concebê-las como antinaturais. Devido às tentativas improfícuas de combater tais evidências acerca das relações de causa e efeito quando quer fundamentá-las com argumentos religiosos, o padre opera um corte no diálogo, vendo a necessidade de falar de religião com o moribundo, já que entende que "amar-te tanto quanto a ti mesmo é aconselhar-te o 
que creio" (2001, p. 23). Para o último, com tom jocoso no diálogo, diz que não há nada mais divertido do que esse assunto, pois é a prova cabal de que, quanto mais religiosas, mais as pessoas foram fanáticas e inconsequentes: "São espécies de desvios prodigiosos como esses que tornam o quadro horrível, mas sempre interessante para mim" (Ibid.)

Rumando ao desfecho do texto, o padre ainda insiste: o moribundo tem de acreditar em algo post mortem, afinal, como não se satisfazer com um sistema em que tudo está arranjado para ações boas serem recompensadas e más ações serem punidas? Contudo, como uma coisa não está necessariamente ligada à outra, já que se pode punir ou recompensar alguém sem merecê-lo, o sistema mais sensato, segundo o moribundo, seria o do nada, que desvenda a falsa liberdade que o homem sempre acreditou ter:

PADRE: - Mas deveis admitir algo após esta vida. É impossível que vosso espírito jamais tenha desejado dissipar as trevas do destino que os aguarda. E qual sistema pode satisfazê-lo melhor do que uma profusão de penas para quem pratica o mal e uma eternidade em recompensas para quem pratica o bem?

MORIBUNDO: - Qual sistema, meu amigo? O do nada, claro. Este jamais me espantou; só vejo nele consolo e simplicidade. Os outros só são obra do orgulho, só ele pertence à razão. Além disso, o nada não é repelente nem absoluto. Não tenho sob os olhos o exemplo de tudo o que é gerado e regenerado perpetuamente pela natureza? Coisa alguma perece ou se destrói no mundo, meu amigo; hoje homem, amanhã verme, depois de amanhã mosca, não é sempre existir? E por que eu seria recompensado por virtudes de que não tenho mérito algum ou punido por crimes de que não fui senhor? Podes conciliar a bondade de teu pretenso deus com esse sistema, e como ele me pode ter criado só para se dar ao prazer de me punir, e ainda em consequência de uma escolha de qual não me deixa ser senhor? (SADE, 2001, p. 26).

Só é possível ainda entender que o homem é totalmente livre se for um preconceituoso, já que o sistema da liberdade do homem foi inventado para engendrar o da graça, alimentador de tudo quanto é desvario. Entre virtudes e vícios, ambos são necessários à natureza, e a sua ciência consistindo em equilibrá-los 
permanentemente, fazendo com que a culpa não seja sentida pela escolha de qualquer um dos lados. ${ }^{7}$ Contudo, o moribundo faz-se entender: não é que o crime mais atroz não deva inspirar horror, mas uma vez cometido, arrependimentos não mudam o fato irreparável. E como evitar o crime? A saber, "[...] pela razão que devemos saber fugir a ele, não por falsas crenças que não levam a nada, e cujo efeito

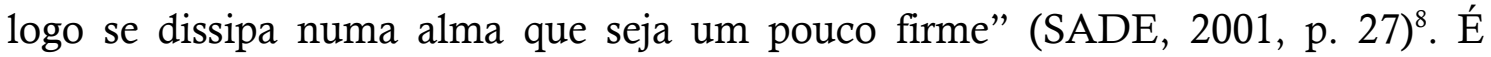
somente a razão que alerta que, prejudicando os outros não se chega à felicidade, e contribuir para a felicidade dos outros é a melhor coisa que a natureza concedeu à humanidade. Assim, não é preciso deus algum para provar os princípios de conduta a serem seguidos, mas somente um coração bom para perceber que isso basta para tornar os nossos próximos tão felizes quanto nós mesmos queremos sê-lo e jamais causar o mal mais do que gostaríamos de receber. O moribundo deixa o mundo proferindo estas palavras ao padre:

\footnotetext{
7 "Somos culpados pelo lado em que ela nos lança? Não mais que a vespa ao aferroar a sua pele" (SADE, 2001, p. 27).

${ }^{8}$ Trecho que parece que não foi lido por Michel Onfray no quarto volume de sua Contra-história da Filosofia: os ultras das Luzes, no qual, em um capítulo sedutor retoricamente, porém, pobre de espírito e ressentido, reduz a filosofia de Sade a uma apologia grosseira da libertinagem e do crime: "[...] se alguns conhecem o nome do escritor, todo o mundo conhece o substantivo sadismo que dele procede" (2012, p. 265-266, grifos do autor). Contudo, totalmente na contramão da leitura de Onfray, Aline Barbosa questiona essa associação anacrônica das obras de Sade a todo tipo de atrocidades contemporâneas: "Haverá mais sadismo em um romance de Sade ou em práticas sádicas de uma vida? Ilse Koch, a abominável 'cadela de Buchenwald', esposa de Karl Otto Koch e comandante dos campos de extermínio de Buchenwald e Majdanek, tornou-se sinistramente famosa por colecionar como souvenir pedaços de peles tatuadas de prisioneiros. As peles viravam capas de livro, luvas, abajures e lustres; órgãos e cabeças encolhidas eram expostos como troféus; polegares mumificados, usados como interruptores. Tratada por sádica pela história, comparada às heroínas criminosas do Marquês, em que medida será de fato uma aliada de Sade, uma de seus pares no domínio da crueldade?" (2020, p. 270) E mais adiante ela afirma: "A recusa sadiana em relação às disciplinas dos homens e a favor da liberdade das paixões oferece possíveis modos de não sucumbir a discursos conservadores que tratam o bem e a lei como valores abstratos e transcendentais. Em vez disso, incita a buscar um trajeto contra-hegemônico capaz de desestabilizar determinadas estruturas para a abertura de novas formas de vida, abafadas pelas convenções sustentadas pelo poder e pela distinção" (Ibid., p. 273). Annie Le Brun assevera que o móbil das falsificações dos escritos de Sade é o interesse ideológico que não mede esforços para caricaturar o autor. Ela cita o exemplo de como o filme Salò, de Pasolini, mostrou a obra Cento e vinte dias de Sodoma: "Il semble même qu'on s'entête à reserver aux Cent vingt journées de Sodome un statut mineur en les réduisant à un catalogue de l'horreur, comme s'il importait avant de tout d'occulter avec la forme prise par ce texte la véritable révolution de la représentation qu'il constitue. Car ce n'est pas l'intêret tapageur que lui a prêté Pasolini pour produire le gigantesque contresens cinématographique de Salo qui a changé quoi que ce soit. Bien au contraire, puisque Pasolini en est arrivé à la falsification pure et simple, dès lors qu'il n'a hésité à plaquer une interprétation idéologique - je parle de sa transposition à l'époque fasciste - sur un texte dont la puissance définitive est d'en dénier la possibilite même" (2004, p. 45).
} 
[...] estou perdendo as minhas forças. Pregador, abandona teus preconceitos, sê homem, sê humano, sem temor nem esperança. Deixa de lado teus deuses e tuas religiões, que só servem para acorrentar os homens; só o nome desses horrores derramou mais sangue sobre a terra do que todas as guerras e flagelos ao mesmo tempo. Renuncia à ideia de outro mundo, que não existe, mas jamais ao prazer em ser e tornar outros felizes neste em que vivemos. Eis o único modo que a natureza oferece para dobrar ou prolongar a sua existência (SADE, 2001, p. 27-28).

\section{Desfalecendo, o moribundo mostra o seu ateísmo consequente - ou "tranquilo", nos} termos de Gilles Deleuze ${ }^{9}$ - pois morreu como viveu. Tranquilidade filosófica diante da morte ${ }^{10}$ que perpassa e predomina em todo o Diálogo, uma vez que os argumentos apresentados pelo personagem religioso, em favor da existência de tudo que ultrapasse o âmbito da matéria, não passa de carolice sob a pena do marquês: "Amigo, parece que tua dialética é tão falsa quanto teu espírito. Gostaria que raciocinasses de modo mais justo, ou que me deixasse morrer em paz" (SADE, 2001, p. 20).

\footnotetext{
${ }^{9}$ Ateísmo tranquilo que Deleuze, atribuindo-o ao pensamento filosófico de François Châtelet, define no início de seu Périclès et Verdi: la philosophie de François Châtelet: "François Châtelet s'est toujours défini comme rationaliste, mais quel rationalisme? Il ne cesse de se référer à Platon, à Hegel, à Marx. Ce qu'il est avant tout, pourtant, c'est aristotélicien. Qu'est-ce qui le distingue alors d'un thomiste? Sans doute, est-ce la manière de récuser Dieu, et tout transcendence. Toutes les transcendences, toutes les croyances en un monde autre, il les appelle 'outrecuidances'. Jamais il n'y a eu de philosophie plus tranquillement athée sauf Nietzsche évidemment. Par athéisme tranquille, nous entendons une philosophie pour qui Dieu n'est pas un problème, l'inexistence ou même la mort de Dieu ne sont pas des problèmes, mais au contraire des conditions qu'il faut considérer comme acquises pour faire surgir les vrais problèmes: il n'y a pas d'autre modestie. Jamais philosophie ne s'est installé plus firmemente dans un champ d'immanence" (1988, p. 7). ${ }^{10}$ Nessa concepção filosófica da morte assentada na serenidade para aceita-la como algo natural e entendida como uma virtude, Sade retoma toda uma tradição socrática, romana e moderna. Vejamos, por exemplo, um trecho do capítulo "De como filosofar é aprender a morrer" (XX), no primeiro volume dos Ensaios de Montaigne. Aqui, o autor inspira-se em Lucrécio e Sêneca: "A existência de que gozais participa da vida e da morte a um tempo; desde o dia de vosso nascimento caminhais concomitantemente na vida para a morte: 'a primeira hora de vossa vida é uma hora a menos que tereis para viver' - 'nascer é começar a morrer; o último instante de vida é consequência do primeiro'. O tempo que viveis, vós o roubais à vida e a restringis proporcionalmente. Vossa vida tem como efeito conduzir-vos à morte. E enquanto viveis estais constantemente sob a ameaça de morte, e mortos, já não viveis mais; ou, se assim preferis, a morte sucede à vida, logo durante a vida estais moribundos; e a morte atinge muitos mais duramente e essencialmente $\mathrm{o}$ moribundo do que o morto. Se soubestes usar a vida e goza-la quanto pudestes, ide-vos e vos declareis satisfeitos: 'por que não sair do banquete da vida como um conviva saciado?' Se não a soubestes usar, se ela vos foi inútil, que vos importa perde-la? E se ela continuasse em que a empregaríeis? 'Para que prolongar dias de que não se saberá tirar melhor proveito do que no passado?' A vida em si não é nem um bem nem um mal. Torna-se bem ou mal segundo o que dela fazeis. E se vivestes um dia já vistes tudo, pois um dia é igual a todos os outros" (1980, p. 49b).
} 


\section{REFERÊNCIAS}

BARBOSA, A. L. F. Espelhos do mal: arquivo e corrupção em Sade. In: Estudos Avançados. São Paulo: USP, 2020, vol.34, n.98, pp.263-278.

BARON D'HOLBACH, P.-H. D. Système de nature ou des lois du monde physique et du monde moral par Mirabaud, avec un discours préliminaire par Naigeon. Genève: Slatkine Prints, 2011.

BLOCH, O. O materialismo. Tradução de Emilio Campos Lima. Mem Martins/Sintra: Publicações Europa-América, 1987.

BORGES, C. Apresentação. In: SADE, M. de. Diálogo entre um padre e um moribundo. Tradução de Alain François e Contador Borges. São Paulo: Iluminuras, 2001.

DELEUZE, G. Périclès et Verdi: la philosophie de François Châtelet. Paris: Les Éditions de Minuit, 1988.

LE BRUN, Annie. L'athéisme, littéralement et dans tous les sens. In: SCLIPPA, N. Lire Sade. Paris: L'Harmattan, 2004, p. 45-54.

MORAES, E.R. Lições de Sade: ensaios sobre a imaginação libertina. São Paulo: Iluminuras, 2006.

MONTAIGNE, M. de. Ensaios. Tradução de Sérgio Milliet. 2a edição. São Paulo: Abril Cultural, 1980 (Coleção "Os Pensadores").

ONFRAY, M. Contra-história da filosofia: 4 - os ultras das Luzes. Tradução de Carla Berliner. São Paulo: Martins Fontes, 2012.

QUINIOU, Y. Athéisme et matérialisme aujourd'hui. Nantes: Éditions Pleins Feux, 2004.

SADE, M. de. Diálogo entre um padre e um moribundo. Tradução de Alain François e Contador Borges. São Paulo: Iluminuras, 2001.

SARTRE, J.-P. O Existencialismo é um Humanismo. Tradução de Rita Correa Guedes. 3a edição. São Paulo: Nova Cultural, 1987 (Coleção "Os Pensadores”). 